Himat Vaghadia MB FRCPC,

Derek Blackstock MB FFARCS(1) FRCPC

\title{
Anaesthetic implica- tions of the trismus pseudocamptodactyly (Dutch-Kentucky or Hecht Beals) syndrome
}

The trismus pseudocampiodactyly syndrome is a relaively rare, autosomal dominant condition first described in 1969. Affected patients classically present with swo main fcaiures: limited excursion of the mandible and flexion deformity of the fingers that occurs with wrist extension (pseudocamptodactyly). Foot deformities and a shorter-than-narmal stature moy also be present. The underlying abnormality is short muscle tendon units, which prevert normal growth and development. We reviewed the anaesthetic experience in three paediatric patients with the trismus pseudocamptodactyly syndrome and the pertinent clinical findings in three other members of the same family, spanning three generations. Limited mandible excursion was presen in all six cases, but was nor obvious preoperatively in the patients because of its subtle presentation. All three cases were successfully managed using mask anaesthesia with spontaneous ventilation, avoiding muscle relaxamts. Attempts to vistalize the larynx under antaesthesia were unsuccessful in tho cases. Blind nasotracheal intubation was successful in one patient. Postoperatively, there were no problems with the airway.

\section{Key words}

GENETIC FACTORS: Trismus pseudocamptodactyly syndrome, Freeman-Sheldon syndrome, Distal Arthrogryposis - Type IIE; ANAESTHESIa: paediatric; ANAESTHETIC TECHNIQUES: inhalational agents; COMPLICATIONS: difficult intubation.

From the Department of Anaesthesia, British Columbia Children's Hospital, Vancouver, British Columbia.

Address correspondence to: Dr. D. Blackstock, Department of Anaesthesia, British Columbia's Children's Hospital, 4480 Oak Street, Vancouver, B.C. V6H 3V4.
Most patients with a difficult airway are easily recognized. Patients with a rare condition whose stigmata are not obvious present a particular danger because the airway abnormality may present for the first time after induction of general anaesthesia. In such a situation, ventilation and tracheal intubation may be difficult or impossible. Trismus pseudocamptodactyly syndrome (TPS) is such a disease.

We review our anaesthetic experience in three cases with TPS and describe the pertinent clinical features in six members of three generations of one family with this disease

Although TPS was first described in $1969,{ }^{1}$ there is little in the medical literature detailing the anaesthetic management of such patients except for a single case report $^{2}$

\section{Case reports}

Case I

This female (Figure 1) was born with equinus and varus deformily of both feet. At the ages of twelve months and eighteen months, she required general anaesthetics for lengthening of both tenda-achilles and flexor hallucis longus tendons, and for manipulations with cast applications. The family history revealed that one cousin had undergone general anaesthesia complicated by difficult intubation - further information was not available. Maximum inter-incisal distance at the age of 18 months was $35 \mathrm{~mm}$ and the remainder of the external examination of the airway was normal. We found no published normal inter-incisal measurements in children below the age of seven years. However, inter-incisal distance in seven-yearold children is normally $36.6 \pm 5.7 \mathrm{~mm}$ (mean \pm SD). ${ }^{3}$

Premedication on both occasions was with chloral hydrate $40 \mathrm{mg} \cdot \mathrm{kg}^{-1}$ and hyoscine $0.008 \mathrm{mg} \cdot \mathrm{kg}^{-1}$. Anaesthesia was induced with nitrous oxide, oxygen, and halothane. On the first occasion, anaesthesia was deepened with halothane in oxygen and laryngoscopy was performed. The vocal cords were seen easily and a $3.5 \mathrm{~mm}$ 
1

II

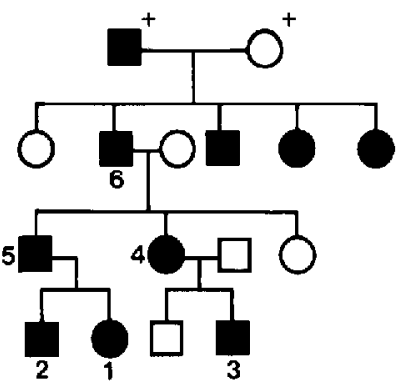

$\square$ male

male with TPS female with TPS

\section{TPS = Trismus pseudocamplodactyly syndrome}

FIGURE I Pedigree of family showing individuals with the Trismus pseudocamptodactyly syndrome. Pedigree numbers identify family members who formed the basis of this report.

endotracheal tube was inserted. Anaesthesia was maintained using the same agents, with the patient breathing spontaneously. On the second occasion, anaesthesia was maintained with the same agents, using a face mask. Postoperatively, there were no airway problems on either occasion. Biopsy of a gastrocnemius muscle, performed to exclude a myopathy, was normal under light and electron microscopy, as was the histochemistry.

\section{Case 2}

This boy, the brother of patient 1 , was scheduled at the age of 22 months for manipulation of both feet and cast applications under general anaesthesia, for the treatment of an equinovarus deformity. The principal clinical findings were: a maximum interincisal distance of $15 \mathrm{~mm}$, pseudocamptodactyly and bilateral contracture of the gastrocnemius-soleus complex and the long toe flexors, producing an equinovarus deformity.

Premedication was with oral chloral hydrate $40 \mathrm{mg} \cdot \mathrm{kg}^{-1}$ and hyoscine $0.008 \mathrm{mg} \cdot \mathrm{kg}^{-1}$. General anaesthesia was induced with nitrous oxide and maintained with oxygen and halothane with spontaneous ventilation by mask.

At the age of 23 months, repeat manipulations of both feet were carried out, using an identical technique. On both occasions, anaesthesia and recovery were uneventful.

At the age of 40 months, the patient was scheduled for surgical correction of the limited excursion of the mandible. Physical examination revealed an inter-incisal distance of $10 \mathrm{~mm}$ (Figures 2 and 3). There was no palpable mandibular condylar motion with jaw opening and the mandible

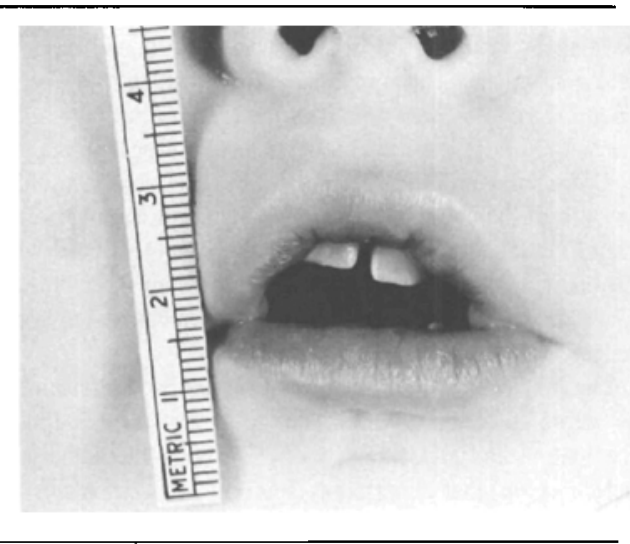

FIGURE 2 Frontal photograph of patient 2, with mouth open to the fullest extent (inter-incisal distance $10 \mathrm{~mm}$ ).

was hypoplastic. In addition, a slight occlusal tilt of the maxillary teeth upward to the right with a right open bite was evident. Roentgenograms of the temporo-mandibular joints were normal except that the condyles did not leave the glenoid fossa with jaw opening. An orthopantogram demonstrated abnormality of the mandible with bilateral elevation and enlargement of the coronoid processes. All other preoperative laboratory investigations were within normal limits.

Premedication was as before. A surgeon experienced in tracheostomy was in attendance. Anaesthesia was induced with nitrous oxide, oxygen, and halothane. The nares were anaesthetized with $0.5 \mathrm{ml}$ of cocaine (four per cent). Although the airway was easy to maintain under general anaesthesia with spontaneous ventilation, the

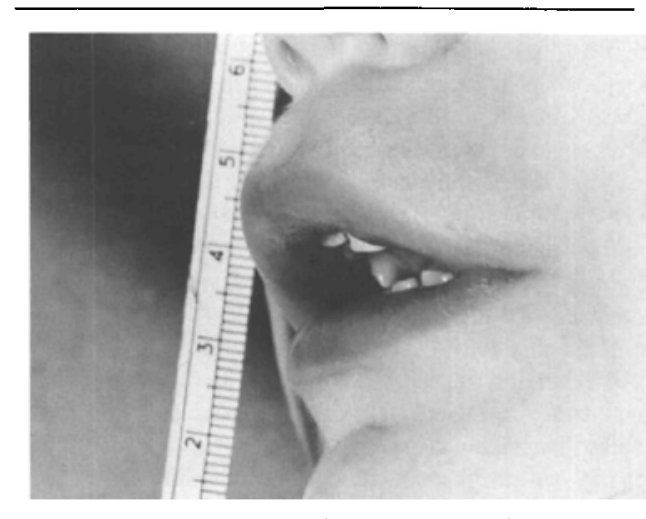

FIGURE 3 Lateral photograph of patient 2, demonstrating limited mandible excursion and a slightly hypoplastic mandible. 
larynx could not be visualized at laryngoscopy. A paediatric flexible bronchoscope was introduced easily into the trachea via the nose. However, a $5.0 \mathrm{~mm}$ uncuffed endotracheal tube could not be inserted into the trachea via the nasotracheal route using the bronchoscope.

During the process, the patient regurgitated a small amount of clear gastric contents and the procedure was therefore abandoned. A postoperative roentgenogram of the chest was compatible with mild aspiration. The child made an uneventful recovery and was rescheduled for repeat surgery in two months.

On this occasion, preoperative findings were the same as before and the chest roentgenogram was normal. Premedication and anaesthetic induction were the same as before except that cimetidine, $3 \mathrm{mg} \cdot \mathrm{kg}^{-1} \mathrm{PO}$, was added to the premedications. Once again, a surgeon experienced in emergency tracheostomy was standing by. Under general anaesthesia, blind nasotracheal intubation with a $4.5 \mathrm{~mm}$ endotracheal tube, employing a stillette was successful. Subsequently, anaesthesia was maintained with nitrous oxide, oxygen, and halothane with spontaneous ventilation. The patient's mouth could not be opened further under general anaesthesia and the maximum inter-incisal distance remained $10 \mathrm{~mm}$. The principal operative findings were bilateral fibrotic bands in the vicinity of the ascending ramus that were indistinguishable from the masseter muscle mass. Bilateral coronoid osteotomies with release of the fibrotic bands increased the inter-incisal distance to $40 \mathrm{~mm}$. At the end of the surgical procedure, trial laryngoscopy was performed under anaesthesia. The posterior glottis was seen but the anterior glottis could not be visualized. The patient was extubated awake and recovery was uneventful.

\section{Case 3}

This boy is the son of patient 4 and a cousin of patients 1 and 2 (Figure 1). He first presented to the Anaesthetic Department at the age of one year when he was scheduled for manipulation of both feet with cast applications. On physical examination, he had an inter-incisal distance of $25 \mathrm{~mm}$. Other findings of note were bilateral congenital vertical talus with varus deformities of the forefeet and pseudocamptodactyly. The remainder of the examination, as well as his preoperative laboratory findings, were normal.

Premedication was with oral hyocsine and chloral hydrate as described above. Anaesthesia was induced and maintained with nitrous oxide, oxygen, and halothane with spontaneous ventilation. During anaesthesia, the airway was maintained with considerable difficulty but, as air entry appeared normal, the anaesthetic was continued. Postoperative recovery was uneventful. Two months later, the patient presented for repeat manipulation of both feet. Anaesthesia was administered by a different anaesthetist, using an identical induction technique after premedication with intramuscular morphine $0.1 \mathrm{mg} \cdot \mathrm{kg}^{-1}$ and hyoscine $0.008 \mathrm{mg} \cdot \mathrm{kg}^{-1}$, and oral pentobarbitone 3 $\mathrm{mg} \cdot \mathrm{kg}^{-1}$. Following induction, limited excursion of the mandible was discovered and once it was realized that the mouth could not be forced open, it was decided to cancel the procedure and wake the child up. Postoperative roentgenograms of the temporomandibular joint were normal.

Between the ages of 15 months and eight and a balf years, this child underwent nine general anaesthetics for minor orthopaedic surgery to his feet. Three different anaesthetists were involved and all were aware of limited excursion of the mandible at the preoperative examination. On three occasions, anaesthesia was induced with thiopentone $5 \mathrm{mg} \cdot \mathrm{kg}^{-1}$ and atropine $0.02 \mathrm{mg} \cdot \mathrm{kg}^{-1}$. The other six anaesthetics had employed inhalation induction technique with nitrous oxide, oxygen, and halothane. On all occasions, anaesthesia was maintained with the nitrous oxide, oxygen and halothane, with spontaneous ventilation. Recovery was uneventful each time. On two occasions, laryngoscopy under halothane anaesthesia was attempted, but the larynx could not be visualized.

\section{Case 4}

This 32-year-old woman is the mother of patient 3 (Figure 1). Her main clinical features were pseudocamptodactyly without foot deformities and an inter-incisal distance of $35 \mathrm{~mm}$. Interincisal distance reported in women is, however, $47.3 \pm 8.8 \mathrm{~mm}$ (mean \pm SD).$^{3}$ She required general anaesthesia for tubal ligation because she refused regional anaesthesia. Following IV sedation with Innovar 0.02 $\mathrm{mg} \cdot \mathrm{kg}^{-1}$ and diazepam $0.1 \mathrm{mg} \cdot \mathrm{kg}^{-1}$, direct laryngoscopy after lidocaine gargle (four per cent) was unsuccessful. Fiberoptic awake intubation with a $7.0 \mathrm{~mm}$ cuffed endotracheal tube was successful. Recovery from anaesthesia was uneventful. Further details regarding her anaesthetic management was not available.

\section{Case 5}

This 31-year-old man is the father of patients 1 and 2 (Figure 1). His maximum inter-incisal distance was 25 $\mathrm{mm}$ (Figute 4 ), inter-incisal distance reported in men is $53.8 \pm 6.5$ mm (mean \pm SD) ${ }^{3}$ Other physical findings of note were pseudocamptodactyly and bilateral contracture of the gastrocnemius-solcus complcx, resulting in an equinovarus deformity. He underwent general anaesthesia for appendectomy as a child. Intubation was not difficult on that occasion but no further details are available. 


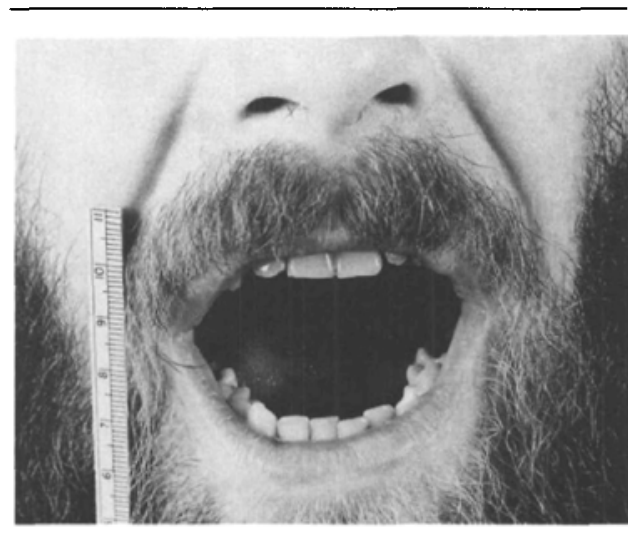

FIGURE 4 Frontal photograph of patient 5 , demonstrating limited mouth opening (inter-incisal distance $25 \mathrm{~mm}$ ).

\section{Case 6}

This 74-year-old man is the grandfather of Patients 1, 2, and 3 . The principal findings of interest in him were an inter-incisal distance of $30 \mathrm{~mm}$, pseudocamptodactyly, and a hammer toe deformity of the right second toe. He underwent general anaesthesia for tonsillectomy as a child. He also required anaesthesia for the repair of bilateral inquinal hemias and a ruptured abdominal aneurysm in his early $60 \mathrm{~s}$. There were no intubation difficulties on any of these occasions. Further details were not available.

\section{Discussion}

Hecht and Beals' first described TPS in 1969 as a genetic condition characterized by: (1) limited excursion of the mandible; (2) deformity of the fingers that occurs with wrist extension (pseudocamptodactyly); and (3) mild short stature. Wilson et al. described a similar case in 1969 and made particular note of the limited jaw excursion and an associated talipes equinovarus. ${ }^{3}$ Foot deformities and a shorter-than-normal stature although seen frequently are not, however, characteristic.

The inheritance pattern is thought to be autosomal dominant. ${ }^{2-5}$ In 1974 , Mabry et al. traced the pedigree of a Kentucky family with TPS. The earliest case that they traced was a Dutch immigrant girl in the southern United States soon after the American Revolution ${ }^{6}$ - hence the term Dutch-Kentucky. She was particularly noted for her small mouth and crooked hands. A six-generation family study by Robertson et al. suggests that TPS has variable expressivity although evidence of reduced penetrance was not present. ${ }^{7}$
The principal anaesthetic implication of TPS is limited excursion of the mandible. Although the underlying mechanism is still debated, there is little doubt that musculoskeletal abnormalities are important. The temporomandibular joint, however, does not seem to be implicated. Thus Hecht and Beals ${ }^{1}$ and Surana and Ives ${ }^{8}$ were unable to find any radiological evidence of temporomandibular joint abnormality. Our findings in cases 2 and 3 were also similar. ter Haar and van Hoof $^{3}$ have suggested that enlarged coronoid processes may be the cause of trismus. They proposed that tension exerted by short temporal muscle tendon units results in enlargement of the coronoid processes. The latter may impinge on the body of the zygomatic bone and inner margin of the arch, thereby limiting mandibular excursion. Mercuri ${ }^{9}$ suggested that not all patients with TPS have enlarged coronoid processes: he proposed that limited excursion of the mandible may also be due to an abnormal ligament between the maxilla and that part of the mandible anterior to the masseter muscles. Our findings in case 2 suggest that fibrotic abnormality of the masseter muscle mass in the vicinity of the ascending ramus may also be an important contributory factor in addition to coronoid enlargement.

Whatever the mechanism of limited mandibular excursion in TPS, it is important to realize that general anaesthetics, muscle relaxants, and physical force will not overcome the problem. Limited excursion of the mandible is present at birth and persists throughout life and, if severe, may require surgical release. Surgical procedures that have been used range from bilateral coronoidotomies with excision of accessory fibrous tissue ${ }^{9}$ to bilateral excision of hypertrophic coronoid processes. ${ }^{10}$ It should not, however, be assumed that surgical therapy of limited mandibular excursion in TPS is necessarily associated with easy laryngoscopy on subsequent occasions. This was confirmed by the experience with case 2 .

Anaesthetists should also be aware that TPS is one of three conditions which are associated with congenital trismus. The other two conditions are: the Whistling Face (Freeman-Sheldon) syndrome and distal arthrogryposis Type IIE. Patients with the Freeman-Sheldon syndrome have a characteristic expression, microstomia, and trismus due to fibrosis of the muscles around the mouth. ${ }^{11,12}$

Distal arthrogryposis (IIE) patients characteristically present with trismus, camptodactyly with hyperextension of the metacarpophalangeal joints and contractures of the hips and feet. ${ }^{13}$ Short stature is present in 43 per cent of cases and a low normal IQ in 35 per cent. Other features that may be seen include micrognathia, scoliosis, small tongue, and facial asymmetry. There appears to be some overlap in the manifestations of TPS, distal arthrogryposis and the Whistling Face syndrome. However, all three con- 
ditions share a constellation of hand and foot deformities that may require orthopaedic surgery. Thus, a safe anaesthetic approach would be to carefully examine all children with familial foot and mouth deformities for evidence of limited mandibular excursion, micrognathia, and dental malocclusion, all of which suggest a potentially difficult intubation.

Various strategies have been described for the anaesthetic management of patients with a "difficult airway." Many of these may be acceptable for use in patients with TPS. We would recommend that anaesthetists choose a technique commensurate with their individual skills and as dictated by the severity of trismus and the surgical needs. Inhalational anaesthesia with spontaneous ventilution may be chosen for minor procedures, provided apptopriate precautions are taken to ensure that the airway can be maintained should intraoperative breathing problems arise. When tracheal intubation is necessary for accessibility or surgical needs, it is important to recognize that blind nasotracheal intubation as well as fiberoptic intubation may not be successful. We would therefore recommend that a surgeon skilled in emergency tracheostomy and cricothryotomy should be in attendance during induction in such cases. In addition, it would be prudent to ensure that such patients are instructed to wear a suitable warning bracelet (e.g., Medic Alert ${ }^{\circledR}$ ).

\section{Summary}

We have described the anaesthetic management of 16 operative procedures in three patients with trismus pseudocamptodactyly syndrome and the pertinent clinical features in six members of the same family over three generations. The main anaesthetic problem associated with this disease is limited mandibular excursion; this may be missed at the prenperative examination unless anaesthetists take special care to look for evidence of trismus in all children with familial hand and foot deformities. Inhalational anaesthesia with spontaneous breathing may be well tolerated in these patients for minor surgery. However, laryngoscopy and intubation may be impossible.

\section{Acknowledgements}

The authors thank Dr. S. J. Tredwell and members of the Anaesthetic Department involved in the care of the patients described in this report for their support as well as Ms. Janice Bak for secretarial assistance. We also thank Dr. D. J. Steward for his editorial assistance.

\section{References}

1 Hecht F, Beals $R K$. Inability to open the mouth fully; an autosomal dominant phenotype with facultative camptodactyly and short stature (preliminary note). $I n$ : Birth Defects: Original Article Series V. (III), Limb Malformations. Bergsma, D (ed). New York, The National Foundation - March of Dimes, 1969; 5: 96-8.

2 Browder FH, Lew D. Shahbazian TS. Anesthetic management of a patient with Dutch-Kentucky Syndrome Anesthesiology, 1986; 65: $218-9$.

3 ier Haar BGA, von Hoof RF. The trismus-pscudocamplodactyly syndrome. J Med Genet 1974; 11: 41-9.

4 Wilson RV, Gaines DL, Brook A et al. Autosomal dominunt inheritance of shortening of the flexor profundus muscle tendon unit with limitation of jaw excursion. $I n$ : Birth Defects: Original Articles Series V (III). Limb Malformations. Bergsma, D (ed). New York, The National Foundations - March of Dimes 1969; 5: 99-102.

5 O'Brien PG, Gropper PT, Tredwell SJ et al. Orthopacdic aspects of the trismus-pseudocamptodactyly syndrome. J Pediatric Orthop 1984; 4: 469-71.

6 Mabry CC. Barnetr IS, Hurcheson MW. Trismus pseudocamptodactyly syndrome: Dutch-Kentucky syndrome. I Pediatrics 1974; 85: 503-8.

7 Robertson RD. Spence MA, Sparkes RS et al. Linkage analysis with trismus-pseudocamptodactyly syndrome. Am J Med Genet 1982; 12: 115-20.

8 Surana $R B$, ives $E J$. Shortened flexor tendons in hands and feet associated with limitation of mouth opening In: Fourth Intemational Congress of Hunan Genetics. Excerpta Medica. Intemational Congress. Excerpta Med. Amsterdam, 1971; No. 233173.

9 Mercuri $L G$. The Hech,, Beals and Wilson syndrome. J Oral Maxillofac Surg 1981; 39: 53-6.

10 Yamushita DR, Arnet GF. Trismus-pseudocamptodactyly syndrome. J Oral Maxillofac Surg 1980; 38: 625-30.

11 Sault JJ, Deianey JR, Regume C ei al. Electromyography of orofacial musculature in craniocarpal-kiasal dysplasia (Freeman-Sheldon syndrome). Clin Genet 1974; 6: 132-7.

12 Laishley RS, Roy WL. Freeman-Sheldon Syndrome: report of three cases and the anaesthetic implications. Can Anaesth Soc J 1986; 33: 388-93.

13 Hall JG, Reed SD, Green A. The Distal Arthrogryposis: Delineation of new entities. Review and nosologic discussion. Am J Med Genet 1982; 11: 185-239. 


\section{Résumé}

Le syndrome de trismus pseudocamptodactylie est relativement rare, autosomal dominant décrit initialement en 1969. Les patients atteints présentent classiquement des caracteristiques majeures: une excursion limitée de la machoire inférieure et une déformilé en flexion des daigts accompagnée d' une extension du poignet (pseudocamptodactylie). Des déformités du pied et une stanure plus courte que la normale peuvent aussi ètre présentes. L'anomalie de base serait des tendons musculaires courts qui empechent la croissance normale et le développement. On a revul'expérience anesthésique chez troir patients pédiatriques ateints de ce syndrome ainsi que dans trois autres membres de la même famille, pour trois générations. La mobilisation limitée de la mandibule était présente chez tous les six cas et n'était pas évidente en période préopératoire à cause de sa présentation subtile. Une conduite anesthésique en masque d ventilasion spontanée êvitant les relaxants musculaires fu utilisée pour tous les trois cas. Des tentatives de visualiser le larynx sous anesthesie ne furent pas possibles dans deux cas. Une intubation nasotrachéale aveugle fut réussie chez un patient, En période postopératoire aucun problème des voies aériennes ne fut noté. 